were laid low by illness, could you give the paper by yourself ?" If the answer is "yes" then the person is an author; if "no" then they receive an acknowledgment.

Department of Medicine,

University Hospital,

J R A Mitchell

\section{Probation linked disulfiram treatment}

SIR,-An extremely disturbing paper by $\mathrm{Dr}$ Colin Brewer and Mr John Smith (29 October $p$ 1282) reported an exercise that entailed the administration of disulfiram to a group of offenders who could have been returned to court if they failed to cooperate.

I am gravely dismayed by this procedure on two counts. Firstly, and most importantly, the ethical justification for this exercise totally escapes me. Secondly, the methodology reported is scientifically unsound.

Dr Brewer and Mr Smith admit that their approach was "authoritarian." It was. They have conducted an exercise that was apparently explicitly designed to be part of the process of law enforcement. In addition, "cooperation" with this venture was encouraged by potentially punitive sanctions. It is amazing that the authors unashamedly advocate the development of this dubious approach. Medicine is not an instrument of social control, except when misused in totalitarian countries. The implications for British medical practice are grave indeed if, in future, the distinction between treatment and punishment is to be wantonly blurred in this way.

Apart from the debatable ethics of their approach, Dr Brewer and Mr Smith have failed to conduct a credible piece of research. No group was used for comparison, and the claim that subjects served as their own controls is forlorn. Individual drinking careers often vary tremendously from time to time: the past need not predict the future. Research simply is not this straightforward, alas. In addition, it appears that lamentably few criteria were used to ascertain the "success" of this venture. Uncorroborated self reports are of extremely doubtful validity when related to subjects who appear to have derived tangible benefits from claiming abstinence.

In summary, this venture was naively conducted, methodologically ramshackle, and ethically precarious. It is not the way forward for the provision of help for habitual drunken offenders. The authors provide no hint of concern with the welfare or social functioning of this group. I sincerely hope that such misguided and sinister experiments will not be replicated.

Alcohol Research Group,

Edinburgh EH 10 5HF

** We sent a copy of this letter to the authors, who reply below.-ED, $B M Y$.

SIR,-That Dr Plant's is the only letter that our paper has provoked suggests that what he describes as "extremely disturbing" has not actually disturbed many people apart from himself. If he were a psychiatrist rather than a sociologist, we think he would not have written: "Medicine is not an instrument of social control except ... in totalitarian countries." There is a large and well established buffer state between crime and disease, signposted by section 37 of the Mental Health Act, for example, and nothing new in the idea that some offenders may be urged by the courts to accept psychiatric treatment as one condition of a probation order. Such an order can be made only with the agreement of the offender and, in contrast to a section 37 order, he may terminate the agreement unilaterally at any time. What new ethical ground is being broken here? In what way is agreeing to take disulfiram as a condition of probation different in principle from agreeing to take a depot neuroleptic?

It may be argued that alcoholism is not a "disease." We think that it is rather like unwanted pregnancy in that, whatever their nosological status, specifically medical techniques of prevention and management exist which make both conditions subjects of legitimate medical concern. If offenders wish to avail themselves of a particular treatment whether as an alternative to the prison sentence they would otherwise have received, or because they feel it will give them the best chance of controlling their drinking and thus avoiding a prison sentence in the future, who is Dr Plant to stand in their way?

As to his methodological criticisms, our research was a pilot study and clearly labelled as such. We made no claims for methodological sophistication or statistical significance. We do not need Dr Plant to remind us that individual drinking careers can vary considerably over time, but we think that it is at least noteworthy that all but one of our subjects exceeded their longest abstinence in the previous two years, usually by a comfortable margin and confirmed by independent observation. The fact that nine of the 16 stopped drinking only after actually giving themselves an alcohol challenge and getting a reaction strongly suggests that without disulfiram, they would have continued to drink and to offend.

Dr Plant's claim that we are unconcerned for the welfare or social functioning of these offenders is easily disproved by our statement: "Disulfiram facilitates rehabilitation but is not a substitute for it."

\section{Community Alcoholism \\ Treatment Service, \\ Westminster Hospital \\ London SW1}

COLIN BREWER

Inner London Probation Service

\section{Variable intrathoracic airways} obstruction masquerading as asthma

SIR,-The respiratory function tests in the case reported by $\mathrm{Mr} \mathrm{C} \mathrm{G} \mathrm{A} \mathrm{McGregor} \mathrm{and}$ others (12 November, $p$ 1457) are described as being "not inconsistent" with asthma. The flow volume loop illustrated in their article shows low flows in inspiration and expiration. Although expired flows show the greater reduction, both parts of the loop are greatly reduced when compared with the predicted flows. The dominant feature of the flow/ volume loop is the plateau of flow at around $1 \mathrm{l} / \mathrm{s}$ during expiration. This is certainly not the usual appearance of the flow volume loop in asthma. In fact it is typical of an obstruction in a large airway. ${ }^{1}$

Although the flow volume loop is helpful in identifying the types of airway obstruction, it is not always readily available. Many GPs, however, have access to a Vitalograph, which plots expired volume against time. We have reprocessed the flow volume loop to obtain the Vitalograph plot that might have been produced by the patient (see figure). Rising as it does in a near straight line at constant flow, it is typical of large airway obstruction.

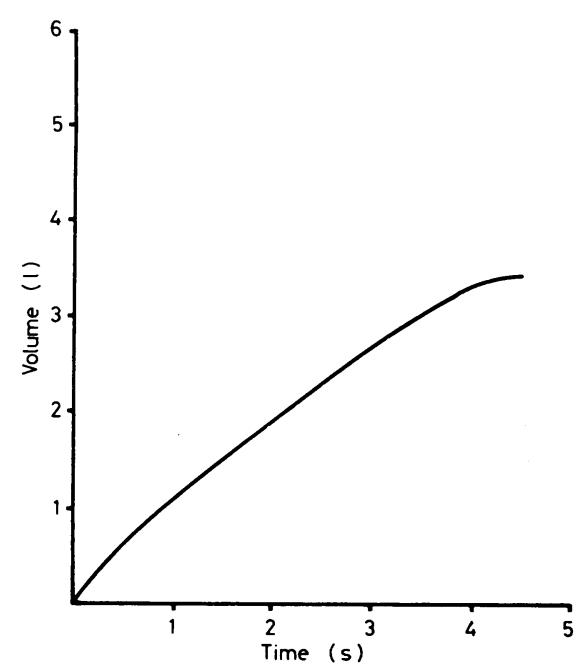

Vitalograph plot of patient with tracheal tumour. Data taken from flow volume loop of $\mathrm{Mr}$ McGregor and others.

In our laboratory we have found that the main use of plotting flow volume loops is to identify local obstructions just like the one in the patient of $\mathrm{Mr}$ McGregor and others. The lesson of their case is not just that, "all that wheezes is not asthma" but that the proper interpretation of respiratory function tests can identify such cases and prevent their inappropriate treatment as asthma.

M A KING

Respiratory Function Unit

STEPHEN J JENNINGS

Department of

Respiratory Medicine,

Guy's Hospital,

London SE1 9R Denison DM, Waller JF, Turton CWG, Sopwith T.
Does the lung work? 5 . Breathing in and breathing out. Br $\mathcal{f}$ Dis Chest 1982;3:237-53.

SIR,-Mr C G A McGregor and others (12 November, p 1457) warn that bronchial obstruction may be mistaken for an apparent asthmatic exacerbation. We should like to report a case of a boy with a known history of asthma whose bronchial tumour was initially diagnosed and treated as a recurrence of asthma.

A 15 year old boy was transferred from another hospital for ventilatory support. He had a history of mild asthma between the ages of 6 months and 6 years that had been successfully controlled with oral salbutamol, with no necessity for hospital admission: he had had no wheezing during the subsequent nine years. He had suffered increasing tiredness for some months, with intermittent abdominal pain and weight loss of $9 \mathrm{~kg}$ ( 1.5 stone) in the month before admission. For two weeks he had had a dry cough but no wheeze until four days before admission, when he was first seen. The diagnosis at this time was a recrudescence of asthma precipitated by contact with pigeons (he had kept racing pigeons for two and a half years), and oral steroids ( $35 \mathrm{mg}$ prednisolone daily) were prescribed. The addition of oral and inhaled salbutamol two days later did not improve his symptoms, and on the day of admission he could not walk and complained of chest pain. His parents noticed he was cyanosed. 